\title{
CRISPR-like sequences in Helicobacter pylori and application in genotyping
}

\author{
Khotchawan Bangpanwimon', Jaksin Sottisuporn², Pimonsri Mittraparp-arthorn', \\ Warattaya Ueaphatthanaphanich ${ }^{3}$, Attapon Rattanasupar ${ }^{4}$, Christine Pourcel $^{5}$ and Varaporn Vuddhakul ${ }^{1 *}$
}

\begin{abstract}
Background: Many bacteria and archaea possess a defense system called clustered regularly interspaced short palindromic repeats (CRISPR) associated proteins (CRISPR-Cas system) against invaders such as phages or plasmids. This system has not been demonstrated in Helicobacter pylori. The numbers of spacer in CRISPR array differ among bacterial strains and can be used as a genetic marker for bacterial typing.

Results: A total of $36 \mathrm{H}$. pylori isolates were collected from patients in three hospitals located in the central (PBH) and southern (SKH) regions of Thailand. It is of interest that CRISPR-like sequences of this bacterium were detected in $\checkmark / p C$ encoded for VacA-like protein C. Virulence genes were investigated and the most pathogenic genotype (cagA vacA $51 \mathrm{~m} 1$ ) was detected in 17 out of $29(58.6 \%)$ isolates from $\mathrm{PBH}$ and 5 out of 7 (71.4\%) from SKH. vapD gene was identified in each one isolate from PBH and SKH. CRISPR-like sequences and virulence genes of 20 isolates of $H$. pylori obtained in this study were analyzed and CRISPR-virulence typing was constructed and compared to profiles obtained by the random amplification of polymorphic DNA (RAPD) technique. The discriminatory power (DI) of CRISPR-virulence typing was not different from RAPD typing.
\end{abstract}

Conclusion: CRISPR-virulence typing in H. pylori is easy and reliable for epidemiology and can be used for inter-laboratory interpretation.

Keywords: Helicobacter pylori, vacA-like gene, vlpC gene, Orphan CRISPR array, CRISPR-like sequences, CRISPR-virulence typing

\section{Background}

Clustered regularly interspaced short palindromic repeats (CRISPR) are detected in around $40 \%$ of bacteria and many archaea $[1,2]$. CRISPR together with the CRISPR-associated genes (cas) are a prokaryotic defense system against invasive bacteriophages or genetic elements. Cas proteins function to degrade foreign nucleic acids of bacteriophages or plasmids. The number of CRISPR loci detected vary between and within bacterial species and strains, 1-4 in Escherichia coli [3], 3 in Yersinia pestis [4], 2 in Salmonella Typhimurium [5], and 1-2 in Staphylococcus aureus [6]. CRISPR loci contain multiple direct repeat (DRs) sequences from 21 to $48 \mathrm{bp}$

\footnotetext{
*Correspondence: varaporn.v@psu.ac.th

1 Department of Microbiology, Faculty of Science, Prince of Songkla

University, Hat Yai, Thailand

Full list of author information is available at the end of the article
}

long separated by variable spacer sequences $21-72$ bp in length [7]. DR sequences are commonly conserved whereas spacer sequences are diverse, and derived from bacteriophages or plasmids. The variable number of DRs and spacers have been used as a typing tool in epidemiologic and evolutionary analysis of bacterial strains [8].

Helicobacter pylori is a Gram negative bacterium that causes peptic ulcer, gastric cancer and mucosa associated lymphoid tissue lymphoma. The risk of disease is associated with $H$. pylori harboring the cytotoxin associated gene $\mathrm{A}$ and vacuolating cytotoxin $\mathrm{A}$, encoded by cagA and $v a c A$ genes respectively. The $\operatorname{cag} A$ gene encodes the bacterial oncoprotein that causes abnormal cellular signals leading to deregulation of cell growth, cell turnover, cell to cell contact, and elongation of epithelial cells. The $v a c A$ gene encodes the pore-forming toxin that induces epithelial cell apoptosis, and inhibits leukocyte activation 
by massive vacuolization, and disruption of the endosome [9]. Allelic variation of $v a c A$ occurs in a signal region $(\mathrm{s} 1 / \mathrm{s} 2)$ and a middle region $(\mathrm{m} 1 / \mathrm{m} 2)$ resulting in different levels of vacuolating cytotoxicity. The vacuolating activity is high in the $\mathrm{s} 1 \mathrm{~m} 1$ genotype whereas the intermediate and absent activities are associated with $\mathrm{s} 1 \mathrm{~m} 2$ and $\mathrm{s} 2 \mathrm{~m} 2$ genotypes, respectively. H. pylori carrying the cagA and $v a c A \operatorname{sim} 1$ allele has been frequently isolated from patients with severe gastric diseases including peptic ulcers, atrophic gastritis, and gastric cancer [10]. The gene encoded for the virulence-associated protein $\mathrm{D}(\operatorname{vapD})$ is present in all virulent strains of ovine footrot bacteria, Dichelobacter nodosus, although the VapD protein function in this bacterium is unknown [11]. This gene has been reported in some H. pylori isolates with $64.9 \%$ nucleotide identity to the vapD gene of $D$. nodosus [12]. The vap region of $D$. nodosus has been demonstrated to harbor genetic element of bacteriophage suggesting the possibility that gene in this region may be transferred among bacteria [13].

In studies of $H$. pylori, biotyping, serotyping and hemagglutinin typing, have been reported to possess low discriminatory power index (DI) compared to genotyping such as RAPD [14], pulse field gel electrophoresis (PFGE) [15], restriction fragment length polymorphismPCR (RFLP-PCR) [16], and repetitive extragenic palindromic PCR fingerprinting (REP-PCR) [17]. PFGE is not widely used for $H$. pylori because inter-patient variation is rare in the fingerprints obtained [18]. The DI of PFGE is between 0.24 and 0.88 whereas RAPD analysis reveals excellent DI (between 0.99 and 1). Thus, RAPD is recommended for $H$. pylori typing [19].

Analysis of the CRISPR-Cas systems in H. pylori has not been clearly demonstrated. The polymorphism detected in CRISPR loci has been applied as a genetic marker for typing many bacteria, such as Campylobacter fetus [20] and S. Typhimurium [5]. In the present study, the CRISPR sequences and virulence genes of this bacterium were investigated and CRISPR-virulence typing was compared to the RAPD.

\section{Methods \\ Isolation and identification of $H$. pylori}

Gastric biopsy samples were obtained from the antral area of patient stomachs in a private hospital in Bangkok $(\mathrm{PBH})$, and two government hospitals in Songkhla (SKH), in the central and southern regions of Thailand, respectively. They were transported in $0.5 \mathrm{ml} \mathrm{BHI}$ broth with vancomycin $10 \mu \mathrm{g} / \mathrm{ml}$, amphotericin B $10 \mu \mathrm{g} / \mathrm{ml}$, trimethoprim $5 \mu \mathrm{g} / \mathrm{ml}$ and polymyxin B $2500 \mathrm{IU} / \mathrm{l}$. The samples were cultured on Columbia sheep blood agar (CBA) and incubated at $37{ }^{\circ} \mathrm{C}$ for 3-7 days under microaerophilic conditions (Oxoid, CampyGen ${ }^{\mathrm{TM}}$ gas generator, United Kingdom). The identification of $H$. pylori was based on colony morphology and biochemical testing. Confirmation was performed by PCR targeted to the ureC $(\mathrm{g} \operatorname{lm} M)$ gene using forward primer (5'-AAGCTTTTAGGGGTG TTAGGGGTTT- $3^{\prime}$ ) and reverse primer $\left(5^{\prime}\right.$-AAGCTT ACTTTCTAACACTAACGC-3') to detect a 294 bp gene fragment [21].

\section{Investigation of CRISPR region in H. pylori}

Five whole genomes of $H$. pylori strains (26695-1MET, XZ274, F57, India7, and SNT49) were analyzed for CRISPR loci using the CRISPRfinder server [22], and specific primers were designed (Table 1). PCR was carried out using PCR mixture containing $5 \times$ PrimeSTAR GXL buffer (Mg2+ plus), 2.5 U PrimeSTAR GXL DNA high-fidelity polymerase (Takara, Shiga, Japan), $0.3 \mathrm{mM}$ dNTPs, $0.4 \mu \mathrm{M}$ of forward and reverse CRISPR-HP primers, and $10 \mu \mathrm{l}$ of template DNA in a total volume of $100 \mu \mathrm{l}$. The PCR process included initial denaturation at $95{ }^{\circ} \mathrm{C}$ for $5 \mathrm{~min}$, followed by 35 cycles of denaturation at $95^{\circ} \mathrm{C}$ for $1 \mathrm{~min}$, annealing at $56^{\circ} \mathrm{C}$ for $1 \mathrm{~min}$, and extension at $68^{\circ} \mathrm{C}$ for $1 \mathrm{~min}$ with a final extension at $68^{\circ} \mathrm{C}$ for $10 \mathrm{~min}$. The PCR products were purified and sequenced.

Table 1 Primers used for detection of virulence genes and CRISPR locus of $\boldsymbol{H}$. pylori

\begin{tabular}{|c|c|c|c|c|}
\hline DNA region(s) amplified & Primer name & Primer sequence & Amplicon sizes(s) (bp) & References or sources \\
\hline $\operatorname{vacAs} \mathrm{s} 1 / \mathrm{s} 2$ & $\begin{array}{l}\text { VAI-F } \\
\text { VAI-R }\end{array}$ & $\begin{array}{l}\text { 5'-ATGGAAATACAACAAACACAC-3' } \\
5^{\prime} \text {-CTGCTTGAATGCGCCAAAC-3' }\end{array}$ & $259 / 286$ & {$[24]$} \\
\hline $\operatorname{vacA} \mathrm{m} 1 / \mathrm{m} 2$ & $\begin{array}{l}\text { VAG-F } \\
\text { VAG-R }\end{array}$ & $\begin{array}{l}\text { 5'-CAATCTGTCCAATCAAGCGAG-3' } \\
\text { 5'-GCGTCAAAATAATTCCAAGG-3' }\end{array}$ & $567 / 642$ & {$[24]$} \\
\hline $\operatorname{cag} A$ & $\begin{array}{l}\text { Cag5c-F } \\
\text { Cag5c-R }\end{array}$ & $\begin{array}{l}\text { 5'-GTTGATAACGCTGTCGCTTC-3' } \\
\text { 5'-GGGTTGTATGATATTTTCCATAA-3' }\end{array}$ & 350 & {$[24]$} \\
\hline $\operatorname{vapD}$ & $\begin{array}{l}D 1-F \\
D 2-R\end{array}$ & $\begin{array}{l}\text { 5'-AGAGATGCGGTGAATGG-3' } \\
\text { 5'-AAGCGTTATGAGTGGTGTG-3' }\end{array}$ & 498 & {$[25]$} \\
\hline CRISPR locus & $\begin{array}{l}\text { CRISPR-HP-F } \\
\text { CRISPR-HP-R }\end{array}$ & $\begin{array}{l}\text { 5'-ATGGGGGCTTTAGTTTCAG-3' } \\
\text { 5'-TAGCAAAAGGCGAACTTGA-3' }\end{array}$ & Variable & This study \\
\hline
\end{tabular}


The direct repeats (DRs) and spacers of the CRISPR loci were analyzed using the CRISPRfinder server. DRs were grouped based on the similarity of consensus direct repeat sequences (CDRs) of each isolate. Clusters of DRs were assigned by multiple sequence alignment (MSA) using MEGA7 software [23]. The spacers of CRISPR were classified according to a phylogenetic tree inferred using MEGA7 software, and the spacer sequences were analyzed using the CRISPRTarget tool (http://bioanalysis. otago.ac.nz/CRISPRTarget/).

\section{Virulence genes investigation}

Multiplex PCR was performed to detect $H$. pylori toxin genes, the cagA gene, and the $\mathrm{s}$ and $\mathrm{m}$ regions of the $v a c A$ gene [24]. DNA template was prepared by boiling technique. The vapD gene was investigated by single PCR, as previously described [25].

\section{RAPD genotyping}

RAPD genotyping was carried out as described previously using primer 1281 (5'-AACGCGCAAC-3'). The RAPD profiles were analyzed with BioNumerics 7.6 (Applied Maths, Belgium), and a dendrogram was constructed by UPGMA method using the Dice similarity coefficient [26].

\section{CRISPR-virulence typing}

CRISPR-virulence typing was based on the CRISPR spacer sequences and the presence of $\operatorname{cag} A$, and $v a c A$ $\mathrm{s}$ and $\mathrm{m}$ regions. A profile of each isolate was created using a binary matrix of presence or absence of spacer sequences and virulence genes. The dendrogram was constructed using BioNumerics 7.6 software with the UPGMA algorithm using the Dice similarity coefficient. The DI of putative CRISPR-virulence typing and RAPD typing were assessed by Simpson's diversity index [27].

\section{Results}

Isolation of $H$. pylori and identification of CRISPR-like sequences

A total of 353 gastric biopsy samples were collected from $\mathrm{PBH}$ and 80 from SKH. Twenty-nine (8.2\%) and seven (8.7\%) isolates of $H$. pylori were identified from $\mathrm{PBH}$ and $\mathrm{SKH}$, respectively. Twenty isolates of $H$. pylori (13 from $\mathrm{PBH}$ and 7 from SKH) were selected for CRISPR analysis and the CRISPR-like sequences were detected in all of the isolates by PCR with amplification products of 280-380 bp. Using the CRISPRfinder server, the numbers of DRs were between 2 and 4 with lengths of 23-31 bp (Table 2). They were divided into 13 DR groups and classified into four clusters (DR-A, B, C and D), each cluster

Table 2 Characteristics of CRISPR-like loci in $\mathbf{2 0 ~ H . ~ p y l o r i ~ i s o l a t e s ~}$

\begin{tabular}{|c|c|c|c|c|}
\hline Isolate & Consensus direct repeats (CDRs) sequences & No. of DRs & No. of spacers & CRISPR-like locus pattern (bp) \\
\hline PBH01 & AACAGCACTITCAATCAAGGGACTTACAA & 4 & 3 & $29-\underline{31}-29-\underline{28}-29-\underline{31}-29$ \\
\hline $\mathrm{PBH} 02$ & TTCAATCAAGGGACTTATAAATT & 3 & 2 & $23-\underline{37}-23-\underline{31}-23$ \\
\hline PBH03 & TTCAATCAAGGGACTTATAGCTT & 3 & 2 & $23-\underline{37}-23-\underline{37}-23$ \\
\hline PBH04 & TTCAATCAAGGGACTTATAAATT & 4 & 3 & $23-\underline{37}-23-\underline{34}-23-\underline{31}-23$ \\
\hline PBH05 & TTCAATCAAGGGACTTATAATTTTA & 4 & 3 & $25-\underline{35}-25-\underline{32}-25-\underline{29}-25$ \\
\hline PBH06 & TTCAATCAAGGGACTTACAAATT & 4 & 3 & $23-\underline{37}-23-\underline{34}-23-\underline{37}-23$ \\
\hline PBH07 & CACTITCAATCAAGGGACTTACAACTTTAAT & 3 & 2 & $31-\underline{29}-31-\underline{26}-31$ \\
\hline PBH08 & TTCAATCAAGGGACTTACAAATT & 4 & 3 & $23-\underline{37}-23-\underline{34}-23-\underline{37}-23$ \\
\hline PBH09 & TTCAATCAAGGGACTTATAAATT & 3 & 2 & $23-\underline{37}-23-\underline{31}-23$ \\
\hline $\mathrm{PBH} 10$ & TTCAATCAAGGGACTTATGACTTTAAT & 2 & 1 & $27-\underline{26}-27$ \\
\hline PBH11 & TTCAATCAAGGGACTTATAATTT & 3 & 2 & $23-\underline{37}-23-\underline{31}-23$ \\
\hline $\mathrm{PBH} 12$ & TTCAATCAAGGGACTTATAATTTTA & 3 & 2 & $25-\underline{35}-25-\underline{29}-25$ \\
\hline PBH13 & TAACTTCAATCAAGGCACTTATCACTTTA & 4 & 3 & $29-\underline{31}-29-\underline{28}-29-\underline{25}-29$ \\
\hline SKH01 & TTCAATCAAGGCACTTATAATTTTA & 3 & 2 & $25-\underline{35}-25-\underline{29}-25$ \\
\hline $\mathrm{SKH} 02$ & TTCAATCAAGGCACTTATCACTTTA & 3 & 2 & $25-\underline{35}-25-\underline{32}-25$ \\
\hline SKH03 & TTCAATCAAGGGACTTACAAATT & 4 & 3 & $23-\underline{37}-23-\underline{34}-23-\underline{37}-23$ \\
\hline SKH04 & TTCAATCAAGGGACTTACAAATT & 4 & 3 & $23-\underline{37}-\underline{23}-\underline{34}-23-\underline{37}-23$ \\
\hline SKH05 & TTCAATCAAGGGACTTATCACTTTA & 4 & 3 & $25-\underline{35}-25-\underline{32}-25-\underline{29}-25$ \\
\hline SKH06 & TTTCAATCAAGGGACTTATAACTTTA & 4 & 3 & $26-\underline{34}-26-\underline{31}-26-\underline{34}-26$ \\
\hline SKH07 & TAACITCAATCAAGGCACTTATCACTTTA & 4 & 3 & $29-\underline{31}-29-\underline{28}-29-\underline{25}-29$ \\
\hline
\end{tabular}

Underline indicates the Consensus sequence

Italic indicates the Direct repeat

Italicunderline indicates the Spacer length 
shared specific sequences within the cluster (Additional file 1: Figure S1). The conserved sequences of DRs of all $H$. pylori isolates were TTCAATCAAGG(G/C)ACTTA (Table 2).

In this work, a total of 50 spacers were detected. The numbers of spacers in each isolate were between 1 and 3 with lengths from 25 to $37 \mathrm{bp}$ (Table 2). They were classified into 28 different spacer patterns and they were not geographical associated (Fig. 1). Using the CRISPRTarget tool and the NCBI database for evaluation, 18 spacers possessed $83-100 \%$ similarity to bacterial plasmid, virus or phage genomes at $\mathrm{E}$ value $\leq 0.18$ (Additional file 2: Table S1).

\section{Virulence genes investigation}

A total of $36 \mathrm{H}$. pylori isolates was investigated for virulence genes. All of them were positive for cagA and $v a c A$ s1 (Table 3). The most pathogenic genotype (cagA vacA s1m1) was detected in 17 out of $29(58.6 \%)$ isolates from $\mathrm{PBH}$ and 5 out of 7 (71.4\%) from SKH. One isolate from each hospital (PBH 06 and SKH 02) was positive for the vapD gene.

\section{Genotyping of H. pylori}

Twenty isolates of $H$. pylori were investigated for RAPD and CRISPR-virulence analysis. All of them exhibited different RAPD profiles with fragments between 0.20 and $4.37 \mathrm{~kb}$ and could be assigned into three clusters (RT-A, RT-B and RT-C) (Fig. 2). Twelve (60\%), seven (35\%) and one (5\%) isolates were classified in the RT-A, RT-B and RT-C clusters, respectively. Isolates in the RT-A cluster were $73 \%$ dissimilar to the isolates in the RT-B cluster whereas the isolate in the RT-C cluster was $90 \%$ dissimilar to the isolates in the RT-A and RT-B clusters.

CRISPR-virulence analysis revealed 20 different profiles which could be classified into two clusters, CVT-A (9 isolates) and CVT-B (11 isolates). The isolates in the CVT-A cluster were $55.9 \%$ dissimilar to the isolates in the CT-B cluster (Fig. 3).

\section{Discussion}

Type II CRISPR-Cas systems are present in Helicobacter cinaedi (NC017761), Helicobacter mustelae (NC013949) and Wolinella succinogenes (NC005090) [28]. In Helicobacter cetorum (NC017737) a type III CRISPR-Cas system is detected. However, no cas gene could be identified in H. pylori, thus CRISPR-like sequences is assigned for the CRISPR loci detected in this work.

It has been reported that H. pylori and several Helicobacter spp. possess $v a c A$-like genes. In $H$. pylori, these genes are designated as imaA (immunomodulatory autotransporter A), faaA (flagella-associated autotransporter A) and $v l p C$ (VacA-like protein C-Vlp C) [29].

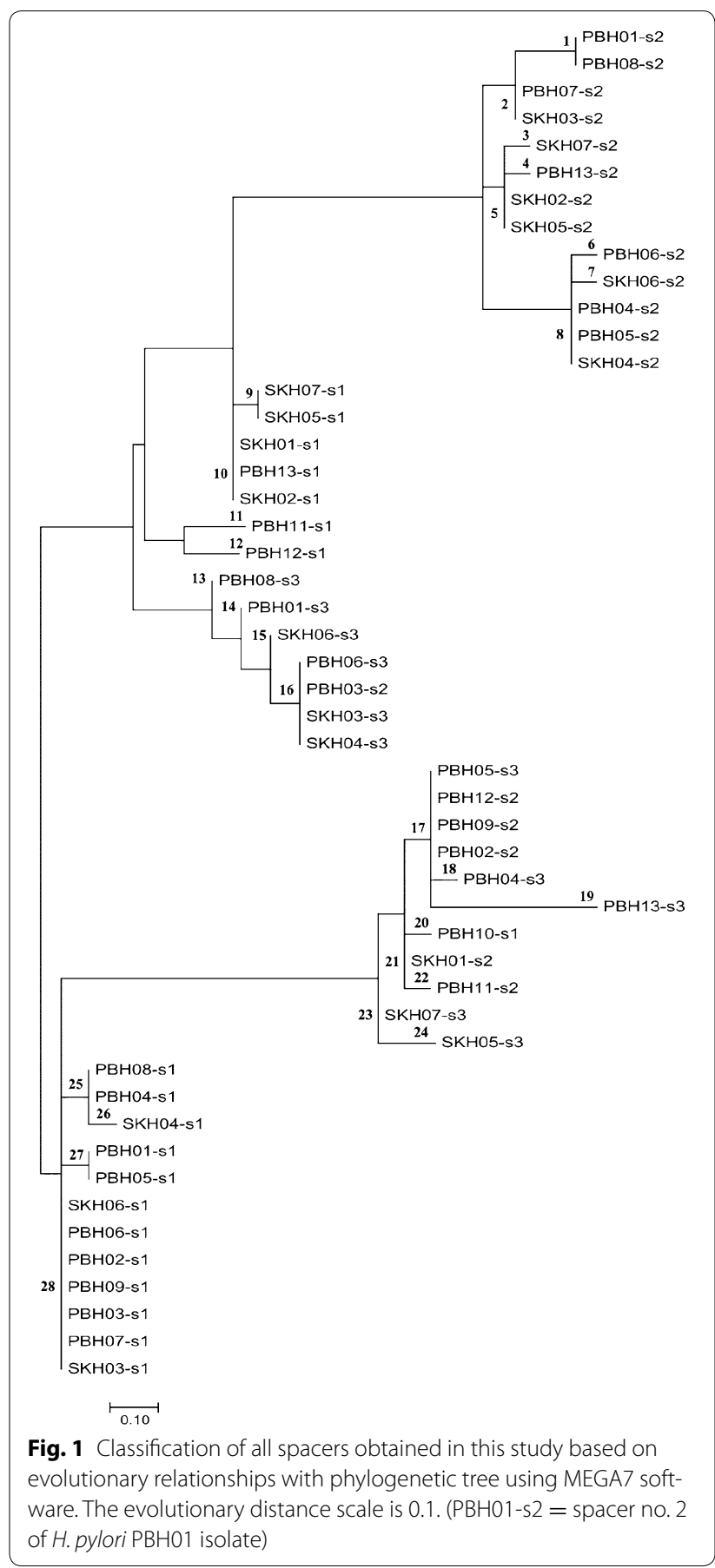

It is of interest that all the CRISPR-like sequences of $H$. pylori identified in this work are located in the $v l p C$ gene (Fig. 4). Analysis of $f a a A$ and $i m a A$ of $5 \mathrm{H}$. pylori isolates (26695-1MET, XZ274, F57, India7, and SNT49) indicated the absence of any CRISPR-like sequences. Although the function of Vlp $\mathrm{C}$ has not been clearly illustrated, mutation of the $v l p C$ gene is associated with the resistance of $H$. pylori to metronidazole [30]. Analysis of $H$. 
Table 3 Virulence genes of $\boldsymbol{H}$. pylori

\begin{tabular}{|c|c|c|}
\hline Isolate & Virulence genotype & vapD gene \\
\hline PBH01 & cagAvacA s1m1 & - \\
\hline $\mathrm{PBH} 02$ & cagAvacA s1m2 & - \\
\hline $\mathrm{PBH} 03$ & cagAvacA s1m2 & - \\
\hline PBHO4 & cagAvacA s1m1 & - \\
\hline PBH05 & cagAvacA s1m1 & - \\
\hline PBH06 & cagAvacA s1m1 & + \\
\hline PBH07 & cagAvacA s $1 \mathrm{~m} 1$ & - \\
\hline PBH08 & cagAvacA s1m1 & - \\
\hline PBH09 & cagAvacA s1m1 & - \\
\hline $\mathrm{PBH} 10$ & cagAvacA s1m2 & - \\
\hline PBH11 & cagAvacA s1m2 & - \\
\hline $\mathrm{PBH} 12$ & cagAvacA s1m1 & - \\
\hline $\mathrm{PBH} 13$ & cagAvacA s1m1 & - \\
\hline PBH14 & cagAvacA s $1 \mathrm{~m} 2$ & - \\
\hline PBH15 & cagAvacA s1m1 & - \\
\hline PBH16 & cagAvacA s1m1 & - \\
\hline PBH17 & cagAvacA s1m2 & - \\
\hline PBH18 & cagAvacA s1m1 & - \\
\hline PBH19 & cagAvacA s1m2 & - \\
\hline PBH2O & cagAvacA s1m1 & - \\
\hline $\mathrm{PBH} 21$ & cagAvacA s1m2 & - \\
\hline $\mathrm{PBH} 22$ & cagAvacA s1m1 & - \\
\hline $\mathrm{PBH} 23$ & cagAvacA s1m2 & - \\
\hline $\mathrm{PBH} 24$ & cagAvacA s1m1 & - \\
\hline $\mathrm{PBH} 25$ & cagAvacA s1m1 & - \\
\hline $\mathrm{PBH} 26$ & cagAvacA s1m1 & - \\
\hline $\mathrm{PBH} 27$ & cagAvacA s1m2 & - \\
\hline $\mathrm{PBH} 28$ & cagAvacA s $1 \mathrm{~m} 2$ & - \\
\hline PBH29 & cagAvacA s1m2 & - \\
\hline SKH01 & cagAvacA s1m1 & - \\
\hline SKH02 & cagAvacA s1m1 & + \\
\hline SKHO3 & cagAvacA s1m2 & - \\
\hline SKH04 & cagAvacA s1m1 & - \\
\hline SKH05 & cagAvacA s1m1 & - \\
\hline SKH06 & cagAvacA s1m2 & - \\
\hline SKH07 & cagAvacA s1m1 & - \\
\hline
\end{tabular}

pylori 26695-1MET Vlp C using the PHYRE2 program (the protein homology/analogy recognition engine $\mathrm{v} 2.0$ ) indicated that this protein was homologous to the viral A-type inclusion protein $\left(\mathrm{E}=2 \times 10^{-69}\right)$ of the Trichomonas vaginalis virus (TVV). Interestingly, the presence of TVV in T. vaginalis causes resistance to metronidazole [31]. The NCBI database indicates that only $H$. pylori and $H$. cetorum harbor this gene. Analysis of $v l p C$ of $H$. pylori F57 and H. cetorum MIT 99-5656 revealed the homology of nucleic sequences to be between 72 and $80 \%$ and this gene contained 2 regions, a high variable region and a low variable region (Fig. 4). The CRISPR-like sequences were identified only in $H$. pylori and were located in the high variable region (between 777 and 1030 nucleotide sequences) with AT-rich leader sequences and contained 2 regions (between 819-916 and 968-1030) homologous to $H$. cetorum sequences. AT-rich leader sequences assumed to be a transcriptional promoter are assigned as one of the CRISPR feature structures [22, 32]. Thus, it is possible that the CRISPR-like sequences were inserted into this part of the $v l p C$ gene, which is not the conserved domain or functional region of the gene. Analysis of 4210 CRISPR arrays revealed $89 \%$ were cas-positive in which 33\% CRISPR arrays were adjacent to a cas locus and $56 \%$ were located outside of cas loci, the rest $11 \%$ were orphans (no cas detected) [33]. It has been demonstrated that orphan CRISPR may involve in gene regulation. In Listeria monocytogenes, orphan CRISPR affects virulence through feo $\mathrm{AB}$ iron transport system [34]. In H. pylori the presence of CRISPR-like sequences in $v l p C$ gene may influence its expression. In vivo investigation of $H$. pylori three $v a c A$-like genes revealed that they were up regulated during colonization of mouse stomach; however, in vitro evaluation of VacA-like proteins in broth culture supernatant using Western blot analysis, ImaA and FaaA were detected but Vlp $C$ was not detected which might be due to it was expressed in the low level [35]. The CRISPRlike sequences of $H$. pylori are detected in the coding region of a $v l p C$ gene, it is uncommon that CRISPR locus of $H$. pylori located in the coding region, however, it has been reported that CRISPR loci I, III, IV and V of Thermotaga maritima were detected in the genes encoded for the hypothetical protein [36]. It is possible that H. pylori acquires those sequences after $v l p C$ gene is already presented in its genome because no CRISPR-like sequences is detected in the $v l p C$ gene of $H$. cetorum.

In this work, we detected 23-31 bp DRs in H. pylori and the number of spacers was between 1 and 3, with 25-37 bp. Twenty-eight spacer patterns were classified from $H$. pylori isolates. Interestingly, $H$. pylori designated as $\mathrm{PBH} 03$ and SKH03 possessed the same virulence gene pattern (Fig. 3) and s1 and s2 spacers of PBH03 were organized in the spacer pattern 28 and 16 respectively which were the same patterns of $\mathrm{s} 1$ and $\mathrm{s} 3$ of SKH03 respectively (Fig. 1). Thus, it is possible that those bacterial isolates might be invaded by the same kind of phage. In this work, some spacers were $83-100 \%$ similar to genetic elements encoding phage DNA polymerase (PBH03-s2, PBH06-s3, SKH03-s3 and SKH04-s3), phage tail protein (PBH13-s2, SKH02-s2 and SKH05-s2) or phage DNA packing protein (SKH04-s1) whereas some spacers were similar to hypothetical proteins derived from bacterial plasmid (PBH06-s1, SKH03-s1, SKH06-s1) 

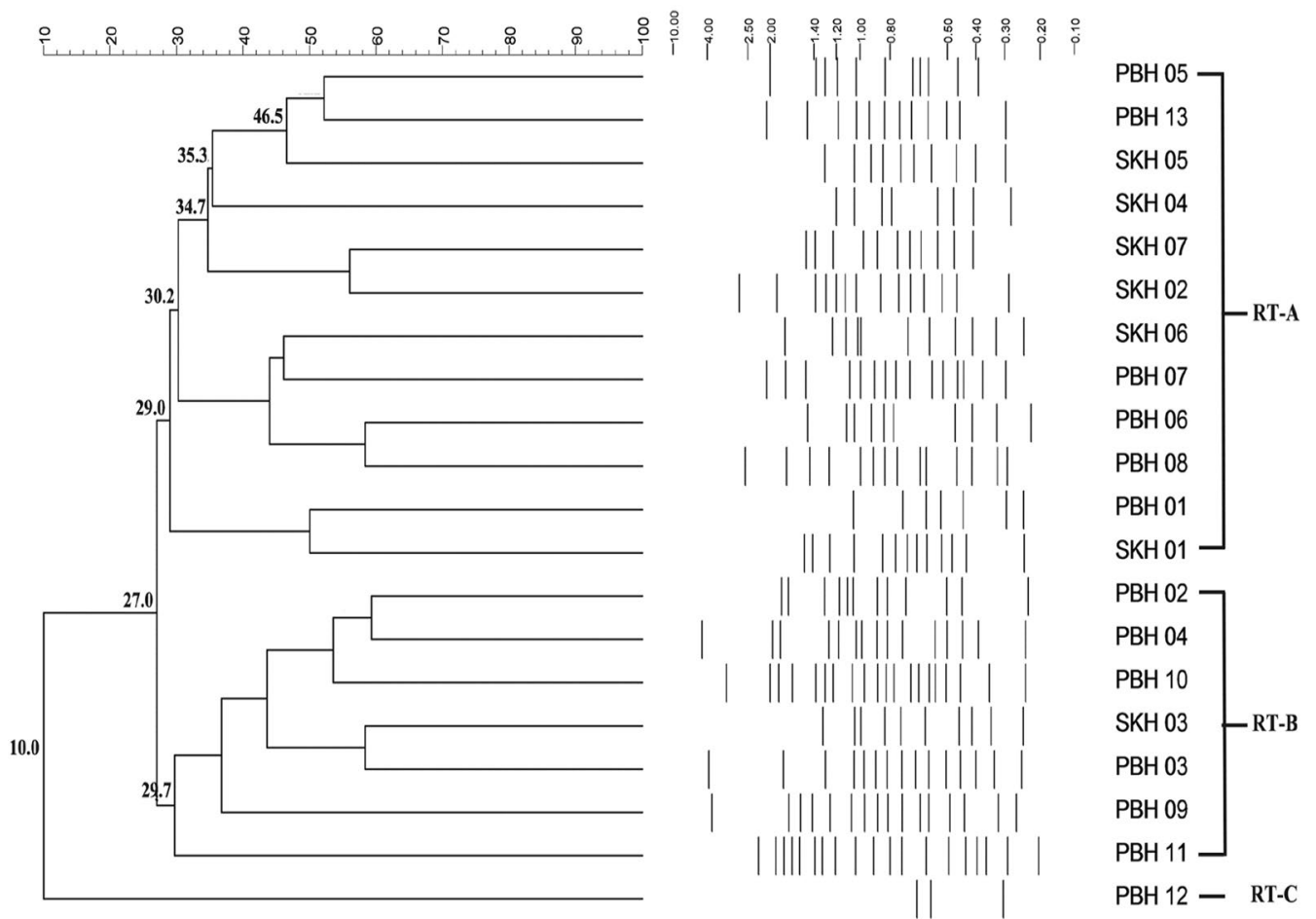

Fig. 2 RAPD analysis of $20 \mathrm{H}$. pylori isolates (PBH = 13) and ( $\mathrm{SKH}=7)$. Phylogenetic analysis was performed using BioNumerrics 7.6. Similarity (\%) between patterns was calculated using the Dice index. The data was sorted using the UPGMA method

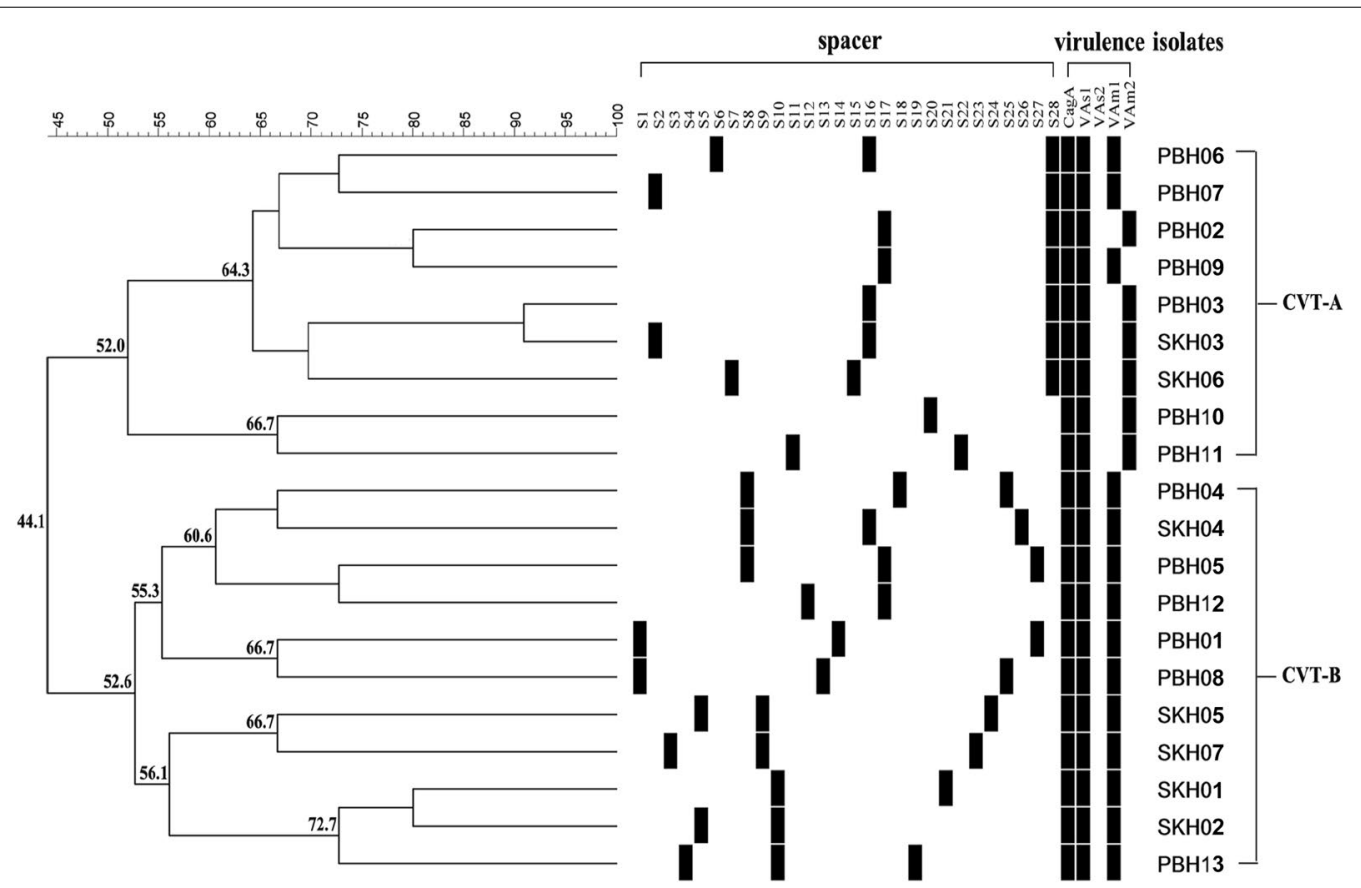

Fig. 3 CRISPR-virulence typing of $20 \mathrm{H}$. pylori isolates from PBH $(n=13)$ and SKH $(n=7)$ base on binary matrix. Phylogenetic analysis was performed using BioNumerrics 7.6. Similarity (\%) between patterns was calculated using the Dice index. The data were sorted using the UPGMA method 


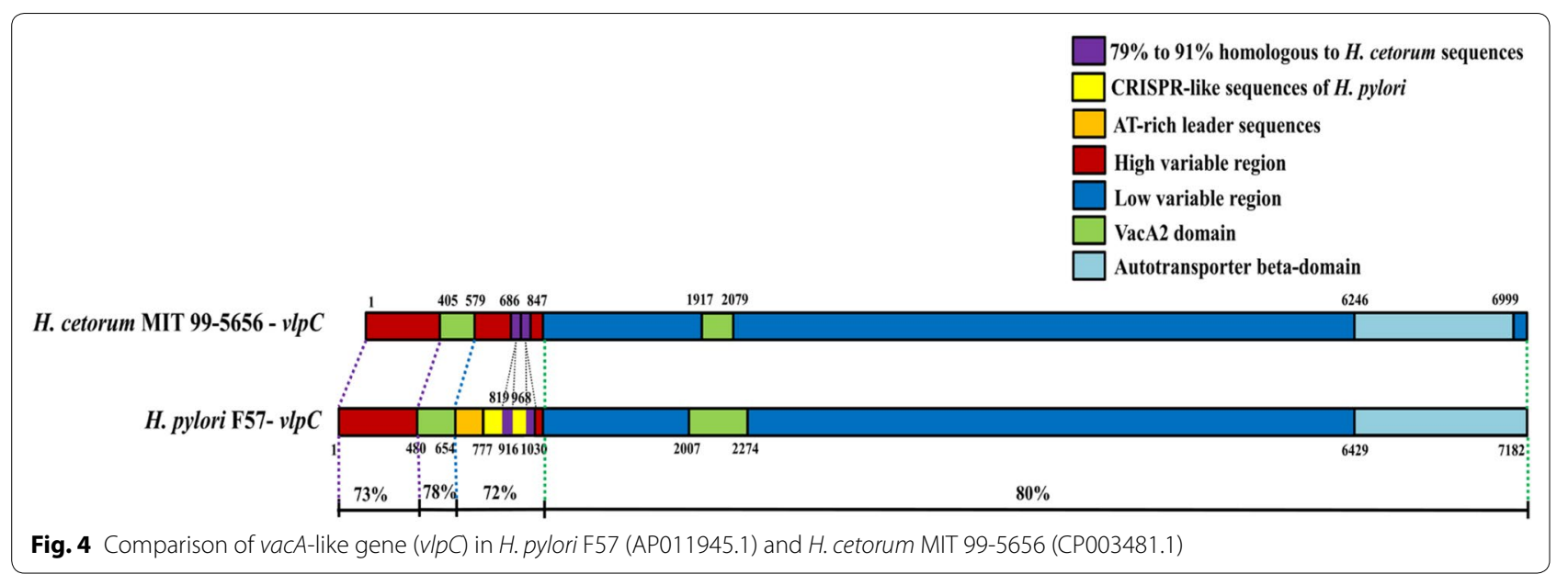

(Additional file 2: Table S1). These genetic elements could be bacterial signatures for typing.

H. pylori cagA $A^{+}$, vacA $\mathrm{s} 1 \mathrm{~m} 1$ strains have been associated in the development of peptic ulcer and gastric carcinoma more than $H$. pylori $c a g A^{-}$, vacA $\operatorname{sim} 2$ strains $[10,37]$. In this work, all $H$. pylori isolates were $c a g A^{+}$strains and the occurrence rate of $v a c A \mathrm{~s} 1 \mathrm{~m} 1$ and $v a c A$ s $1 \mathrm{~m} 2$ strains was $61.1 \%(22 / 36)$ and $38.9 \%(14 / 36)$, respectively. All vacA $\mathrm{m} 2 \mathrm{H}$. pylori isolates were organized in the CVT-A cluster of CRISPR-virulence typing (Fig. 3). The previous studies of $H$. pylori in Thailand demonstrated that 95\% of isolates were $\operatorname{cag} A^{+}$whereas the $v a c A$ s $1 \mathrm{~m} 1$ and $\mathrm{s} 1 \mathrm{~m} 2$ genotypes were found in 65 and $35 \%$ of total isolates, respectively [38]. In this study, the prevalence rate of pathogenic H. pylori (cagA $A^{+}$vacA $\mathrm{s} 1 \mathrm{~m} 1$ ) in samples collected in the southern region was $71.4 \%$ which was significantly higher than the prevalence rate in the samples from the central region (58.6\%).

H. pylori VapD protein possesses endoribonuclease activity and may be involved in cell maintenance or the protection of foreign genetic elements [39, 40]. It is of interest that only $5.5 \%(2 / 36)$ of $H$. pylori obtained in this work were positive for the vapD gene whereas it was present in $38.0 \%$ of $\mathrm{H}$. pylori isolates from Mexico and $61.3 \%$ from the USA [12, 25]. Using hybridization and confirmation by sequencing, it has been demonstrated that vapDnegative $H$. pylori isolates possessed high-level genetic diversity in the vapD region [12]. Differences in the detection of this gene in Asian (Thailand) and Western (Mexico and USA) $H$. pylori isolates should be explored.

Various patterns of spacers in the CRISPR-Cas system have been reported for subtyping C. jejuni, Mycobacterium tuberculosis, Erwinia amylovora, V. parahaemolyticus and S. enterica [8, 20, 41]. Analysis of orphan CRISPR spacers derived from 14 clinical Enterococcus faecalis isolates indicates two groups of clonal strains which correlates to the Multilocus sequence typing (MLST) [42]. Better bacterial discrimination through a combination of CRISPR pattern and virulence gene typing has been demonstrated [43, 44]. In the present study, the DI of CRISPR-virulence typing was higher than that of CRISPR typing alone (Additional file 3: Table S2). Analysis of 20 profiles derived from CRISPR-virulence typing and RAPD revealed that DIs of both techniques were 1 . However, RAPD seems to be better than CRISPRvirulence typing because it could differentiate $H$. pylori PBH12 from the other strains (Fig. 2) whereas only two clusters were obtained from CRISPR-virulence typing (Fig. 3). This might be due to the low number of spacers detected in the tested isolates in this work. However, the reproducibility of RAPD is poor and the method lacks validated interpretation criteria for inter-laboratory comparison [18, 45]. CRISPR-virulence typing is more reliable for long-term global epidemiology and evolutionary studies and the CRISPR locus databank is excellent for inter-laboratory interpretation and inter-laboratory reproducibility. The information of the CRISPR-like sequences in $H$. pylori acquired in this work expands the basic knowledge for typing of bacteria.

\section{Conclusions}

This is the first report of CRISPR-like sequences in $H$. pylori which was detected in the $v l p C$ gene. Twentyeight different spacers with the numbers between 1 and 3 were identified and can be used as bacterial signature for genotyping. In this work, CRISPR-virulence typing of H. pylori was performed and compared with the RAPD. Their DIs were not different. However, RAPD is poor reproducible and lacks validated interpretation criteria for inter-laboratory comparison. Therefore, CRISPR-virulence typing is a novel epidemiological tracking tool for H. pylori management. 


\section{Additional files}

Additional file 1: Figure S1. Clusters of DR assigned in H. pylori based on multiplex sequence alignment using MEGA7 software (highlight indicated the share sequences within the cluster).

Additional file 2: Table S1. Genetic elements exhibiting similarity to spacer sequences

Additional file 3: Table S2. Discriminatory power (DI) of H. pylori genotyping.

\section{Authors' contributions}

Conceptualization: W. Formal analysis: CP, PM, JS. Investigation: KB, JS, PM, WU, AR. Methodology: KB, PM. Supervision: WV. All authors read and approved the final manuscript.

\begin{abstract}
Author details
${ }^{1}$ Department of Microbiology, Faculty of Science, Prince of Songkla University, Hat Yai, Thailand. ${ }^{2}$ NKC Institute of Gastroenterology and Hepatology, Songklanagarind Hospital, Faculty of Medicine, Prince of Songkla University, Hat Yai, Thailand. ${ }^{3}$ Microbiology Laboratory, Vichaiyut Hospital, Bangkok, Thailand. ${ }^{4}$ KC Center of Gastroenterology and Hepatology, Hat Yai Hospital, Hat Yai, Thailand. ${ }^{5}$ Institute for Integrative Biology of the Cell (I2BC), CEA, CNRS, Univ. Paris-Sud, Université Paris-Saclay, Gif-sur-Yvette, France.
\end{abstract}

\section{Competing interests}

The authors declare that they have no competing interests.

\section{Availability of data and materials}

All data generated or analyzed during this study are included in the published article.

\section{Consent for publication}

Not applicable.

\section{Ethic approval and consent to participate}

This work has been approved by the Office of Human Research Ethics Committee (HREC), Prince of Songkla University, Thailand (EC: 58-241-19-2).

\section{Funding}

This work was financially supported by the Thailand Research Fund (TRF) through the Royal Golden Jubilee Ph.D. Program (Grant No. PHD/0224/2558) and the Prince of Songkla University through the Scholarship for Outstanding GPA.

\section{Publisher's Note}

Springer Nature remains neutral with regard to jurisdictional claims in published maps and institutional affiliations.

Received: 7 October 2017 Accepted: 6 November 2017

Published online: 17 November 2017

\section{References}

1. Kunin V, Sorek R, Hugenholtz P. Evolutionary conservation of sequence and secondary structures in CRISPR repeats. Genome Biol. 2007;8:R61.

2. Marraffini LA, Sontheimer EJ. CRISPR interference: RNA-directed adaptive immunity in bacteria and archaea. Nat Rev Genet. 2010;11:181-90.

3. Rahmatabadi SS, Nezafat N, Negahdaripour M, Hajighahramani N, Morowvat MH, Ghasemi Y. Studying the features of 57 confirmed CRISPR loci in 29 strains of Escherichia coli. J Basic Microbiol. 2016;56:645-53.

4. Pourcel C, Salvignol G, Vergnaud G. CRISPR elements in Yersinia pestis acquire new repeats by preferential uptake of bacteriophage DNA, and provide additional tools for evolutionary studies. Microbiology. 2005;151:653-63.

5. Almeida F, Medeiros MIC, dos Prazeres Rodrigues D, Allard MW, Falcão JP. Molecular characterization of Salmonella Typhimurium isolated in Brazil by CRISPR-MVLST. J Microbiol Methods. 2017;133:55-61.

6. Yang S, Liu J, Shao F, Wang P, Duan G, Yang H. Analysis of the features of 45 identified CRISPR loci in 32 Staphylococcus aureus. Biochem Biophys Res Commun. 2015;464:894-900.

7. Barrangou R, Horvath P. CRISPR: new horizons in phage resistance and strain identification. Annu Rev Food Sci Technol. 2012;3:143-62.

8. Shariat N, Dudley EG. CRISPRs: molecular signatures used for pathogen subtyping. Appl Environ Microbiol. 2014;80:430-9.

9. Kusters JG, van Vliet AH, Kuipers EJ. Pathogenesis of Helicobacter pylor infection. Clin Microbiol Rev. 2006;19:449-90.

10. Wroblewski LE, Peek RM, Wilson KT. Helicobacter pylori and gastric cancer: factors that modulate disease risk. Clin Microbiol Rev. 2010;23:713-39.

11. Katz ME, Howarth PM, Yong WK, Riffkin GG, Depiazzi LJ, Rood JI. Identification of three gene regions associated with virulence in Dichelobacter nodosus, the causative agent of ovine footrot. J Gen Microbiol. 1991;137:2117-24.

12. Cao P, Cover TL. High-level genetic diversity in the vapD chromosomal region of Helicobacter pylori. J Bacteriol. 1997;179:2852-6.

13. Cheetham BF, Katz ME. A role for bacteriophages in the evolution and transfer of bacterial virulence determinants. Mol Microbiol. 1995;1:201-8.

14. Akopyanz N, Bukanov NO, Westblom TU, Kresovich S, Berg DE. DNA diversity among clinical isolates of Helicobacter pylori detected by PCR-based RAPD fingerprinting. Nucleic Acids Res. 1992;20:5137-42.

15. Park C-Y, Kwak M, Gutierrez O, Graham DY, Yamaoka Y. Comparison of genotyping Helicobacter pylori directly from biopsy specimens and genotyping from bacterial cultures. J Clin Microbiol. 2003;41:3336-8.

16. Akopyanz N, Bukanov NO, Westblom TU, Berg DE. PCR-based RFLP analysis of DNA sequence diversity in the gastric pathogen Helicobacter pylori. Nucleic Acids Res. 1992;20:6221-5.

17. Kwon DH, El-Zaatari FA, Woo JS, Perng CL, Graham DY, Go MF. REP-PCR fragments as biomarkers for differentiating gastroduodenal diseasespecific Helicobacter pylori strains. Dig Dis Sci. 1998;43:980-7.

18. Colding H, Hartzen SH, Roshanisefat H, Andersen LP, Krogfelt KA. Molecular methods for typing of Helicobacter pylori and their applications. FEMS Immunol Med Microbiol. 1999;24:193-9.

19. Burucoa C, Lhomme V, Fauchere JL. Performance criteria of DNA fingerprinting methods for typing of Helicobacter pylori isolates: experimental results and meta-analysis. J Clin Microbiol. 1999;37:4071-80.

20. Calleros L, Betancor L, Iraola G, Méndez A, Morsella C, Paolicchi F, Silveyra S, Velilla A, Pérez R. Assessing the intra-species genetic variability in the clonal pathogen Campylobacter fetus: CRISPRs are highly polymorphic DNA markers. J Microbiol Methods. 2017:132:86-94.

21. Lage AP, Godfroid E, Fauconnier A, Burette A, Butzler JP, Bollen A, Glupczynski Y. Diagnosis of Helicobacter pylori infection by PCR: comparison with other invasive techniques and detection of cagA gene in gastric biopsy specimens. J Clin Microbiol. 1995;33:2752-6.

22. Grissa I, Vergnaud G, Pourcel C. CRISPRFinder: a web tool to identify clustered regularly interspaced short palindromic repeats. Nucleic Acids Res. 2007:35:W52-7.

23. Kumar S, Stecher G, Tamura K. MEGA7: molecular evolutionary genetics analysis version 7.0 for bigger datasets. Mol Biol Evol. 2016;33:1870-4.

24. Chattopadhyay S, Patra R, Ramamurthy T, Chowdhury A, Santra A, Dhali G, Bhattacharya S, Berg DE, Nair GB, Mukhopadhyay AK. Multiplex PCR assay for rapid detection and genotyping of Helicobacter pylori directly from biopsy specimens. J Clin Microbiol. 2004;42:2821-4.

25. Morales-Espinosa R, González-Valencia G, Delgado G, Méndez JL, Torres J, Cravioto A. Frequency and characterization of vapD gene in Helicobacter pylori strains of different vacA and cag-PAl genotype. Bioquimia. 2008;33:43-50

26. Berg DE, Lelwala-Guruge J, Incecik ET, Srivastava K, Akopyants NS. H. pylori DNA fingerprinting using the arbitrarily primed PCR (AP-PCR) or random amplified polymorphic DNA (RAPD) method. Methods Mol Med. 1997:8:117-32

27. Hunter PR, Gaston MA. Numerical index of the discriminatory ability of typing systems: an application of Simpson's index of diversity. J Clin Microbiol. 1988;26:2465-6. 
28. Burstein D, Harrington LB, Strutt SC, Probst AJ, Anantharaman K, Thomas BC, Doudna JA, Banfield JF. New CRISPR-Cas systems from uncultivated microbes. Nature. 2017;542:237-41.

29. Foegeding NJ, Caston RR, McClain MS, Ohi MD, Cover TL. An overview of Helicobacter pylori VacA toxin biology. Toxins. 2016;8:173. https://doi. org/10.3390/toxins8060173.

30. Albert TJ, Dailidiene D, Dailide G, Norton JE, Kalia A, Richmond TA, Molla M, Singh J, Green RD, Berg DE. Mutation discovery in bacterial genomes: metronidazole resistance in Helicobacter pylori. Nat Methods. 2005;2:951-3.

31. Conrad MD, Gorman AW, Schillinger JA, Fiori PL, Arroyo R, Malla N, Dubey ML, Gonzalez J, Blank S, Secor WE, et al. Extensive genetic diversity, unique population structure and evidence of genetic exchange in the sexually transmitted parasite Trichomonas vaginalis. PLoS Negl Trop Dis. 2012;6:e1573. https://doi.org/10.1371/journal.pntd.0001573.

32. Sorek R, Kunin V, Hugenholtz P. CRISPR - a widespread system that provides acquired resistance against phages in bacteria and archaea. Nat Rev Microbiol. 2008;6:181-6.

33. Makarova KS, Wolf YI, Alkhnbashi OS, Costa F, Shah SA, Saunders SJ, Barrangou R, Brouns SJ, Charpentier E, Haft DH, et al. An updated evolutionary classification of CRISPR-Cas systems. Nat Rev Microbiol. 2015;13:722-36.

34. Westra ER, Buckling A, Fineran PC. CRISPR-Cas systems: beyond adaptive immunity. Nat Rev Microbiol. 2014;12:317-26.

35. Radin JN, Gaddy JA, Gonzalez-Rivera C, Loh JT, Algood HM, Cover TL. Flagellar localization of a Helicobacter pylori autotransporter protein. MBio. 2013;4(2):e00613.

36. Nelson KE, Clayton RA, Gill SR, Gwinn ML, Dodson RJ, Haft DH, Hickey EK, Peterson JD, Nelson WC, Ketchum KA, et al. Evidence for lateral gene transfer between Archaea and bacteria from genome sequence of Thermotoga maritima. Nature. 1999;399:323-9.

37. Bridge DR, Merrell DS. Polymorphism in the Helicobacter pylori CagA and VacA toxins and disease. Gut Microbes. 2013:4:101-17.
38. Sahara S, Sugimoto M, Vilaichone R-K, Mahachai V, Miyajima H, Furuta T, Yamaoka Y. Role of Helicobacter pylori cagA EPIYA motif and vacA genotypes for the development of gastrointestinal diseases in Southeast Asian countries: a meta-analysis. BMC Infect Dis. 2012;12:223.

39. Kwon AR, Kim JH, Park SJ, Lee KY, Min YH, Im H, Lee I, Lee KY, Lee BJ. Structural and biochemical characterization of HP0315 from Helicobacter pylori as a VapD protein with an endoribonuclease activity. Nucleic Acids Res. 2012;40:4216-28.

40. Louwen R, Staals RH, Endtz HP, van Baarlen P, van der Oost J. The role of CRISPR-Cas systems in virulence of pathogenic bacteria. Microbiol Mol Biol Rev. 2014:78:74-88.

41. Sun H, Li Y, Shi X, Lin Y, Qiu Y, Zhang J, Liu Y, Jiang M, Zhang Z, Chen Q. Association of CRISPR/Cas evolution with Vibrio parahaemolyticus virulence factors and genotypes. Foodborne Pathog Dis. 2015;12:68-73.

42. Hullahalli K, Rodrigues M, Schmidt BD, Li X, Bhardwaj P, Palmer KL. Comparative analysis of the orphan CRISPR2 locus in 242 Enterococcus faecalis strains. PLoS ONE. 2015;10(9):e0138890.

43. Liu F, Barrangou R, Gerner-Smidt P, Ribot EM, Knabel SJ, Dudley EG. Novel virulence gene and clustered regularly interspaced short palindromic repeat (CRISPR) multilocus sequence typing scheme for subtyping of the major serovars of Salmonella enterica subsp. enterica. Appl Environ Microbiol. 2011;77:1946-56.

44. Shariat N, DiMarzio MJ, Yin S, Dettinger L, Sandt CH, Lute JR, Barrangou R, Dudley EG. The combination of CRISPR-MVLST and PFGE provides increased discriminatory power for differentiating human clinical isolates of Salmonella enterica subsp. enterica serovar Enteritidis. Food Microbiol. 2013:34:164-73.

45. Gherardi G, Creti R, Pompilio A, Di Bonaventura G. An overview of various typing methods for clinical epidemiology of the emerging pathogen Stenotrophomonas maltophilia. Diagn Microbiol Infect Dis. 2015;81:219-26.

\section{Submit your next manuscript to BioMed Central and we will help you at every step:}

- We accept pre-submission inquiries

- Our selector tool helps you to find the most relevant journal

- We provide round the clock customer support

- Convenient online submission

- Thorough peer review

- Inclusion in PubMed and all major indexing services

- Maximum visibility for your research

Submit your manuscript at www.biomedcentral.com/submit
O Biomed Central 